micturate, and these extended over some weeks. The tumour remained in situ, however, and there has been no sign of its reappearance since. I cannot say, however, that the operation has benefited the patient very much. She is nearly as low-spirited as ever, and though there is less abdominal pain than before, there is still a good deal, and the calls to micturate are still abnormally frequent. Possibly the near advent of the menopause may partially explain her symptoms.

Remarks.-I am no advocate of operative procedure in the case of either movable o: floating kidney, and what was done in this case was rather as a sequel to an exploratory operation than as a deliberate attempt at fixation of the kidney. It would have been easy to stitch the kidney to the abdominal wall ; but it is difficult to believe that an un protected position close to the surface of the abdomen and in contact with its constantly moving walls can be much better than free movement inside the abdominal cavity. Again, might have cut down on the kidney in the loin, and stitched its capsule to the tissues in the neighbourhood. This would have added to the danger of the operation, and would have rendered only the immediate result more certain, for sutures fixate only as long as they exist. When these are absorbed, the adhesions only remain to connect the united surfaces, and if the artificially inflamed capsule is kept in position while the adhesions consolidate the effect of sutures might be got. In this case, now that a year has passed, we may assume that the desired result has been attained. In another case I should give a thorough trial to treatment by rest in bed, and carefully applied padding inside an abdominal belt. If this failed, I should perform nephrorraphy by lumbar incision. But a case such as the above teaches us not be too sanguine as to the immediate good result of fixation, and should warn us to hold our hands for a long time unless the local symptoms were very urgent indeed.

Clifton.

\section{FIVE YEARS OF THE COMPULSORY NOTI- FICATION OF INFECTIOUS DISEASES IN JARROW.}

BY A. CAMPBELL MUNRO, M.B., M.R.C.P.E., D.Sc., MEDICAL OFFICER OF HEALTH FOR SOUTH SHIELDS AND JARROW.

AT a time when the question of the compulsory notifica tion of infectious diseases is being hotly debated, and its extension to various individual towns vigorously opposed, it may be serviceable that some statement of the results of the adoption of the system in one of the towns in which it was first introduced should be laid before the profession.

The Jarrow Improvement Act, which came into operation at the end of 1878 , includes the following sections, which detail the conditions of the notification system as adopted by the corporation of that borough:-

" 35 . In order to secure that due notice be given to the corporation of any inmate of any house who is suffering from infectious disease, the following provisions shall have effect (that is to say): (a) If any inmate be suffering from any such disease as aforesaid, the occupier or person having the management or control of such house shall, so soon as he becomes aware of the existence in any such inmate of any such disease, forthwith give notice thereof to the corporation. (b) If such inmate be not a member of the family of such occupier or person, then such inmate or the person having charge of such inmate shall, on becoming aware of the existence of such disease, forthwith give notice thereof to the corporation. (c) If such inmate so suffering as aforesaid is attended by a medical practitioner, such practitioner shall, on becoming aware that such inmate is suffering from any such disease as aforesaid, forthwith fill up, sign, and send to the corporation at the Town Hall a certificate or declaration stating, according to the forms prescribed and supplied to him by the corporation, the name of such inmate, the situation of such house, and the name of such occupier or person, and the nature of the disease from which inmate is suffering. (d) The corporation shall pay to every medical practitioner a fee of one shilling for every certificate or declaration given by him under this section. Only one such fee shall be payable in the case of one and same illness in the same house or family. (e) The corporation shall provide and supply gratuitously to every registered medical practitioner resident or practising in the borough forms for the certificate or declaration by such medical practitioner of the particulars berein mentioned in relation to such cases, according to the form set forth in the schedule to this Act. In this section 'house' includes any part of a house, and any building for the time being used for human habitation.

" 36 . Any person wilfully or without reasonable excuse offending against any provision of this part of this Act, or any order or regulation made under the provisions of this part of this Act, shall be liable on summary conviction to a penalty not exceeding five pounds, and in case of a continuing offence, to a further penalty not exceeding forty shillings for every day on which such offence continues."

Infectious disease is defined in Section 2 of the Act as meaning "small-pox, cholera, and fever." It will be seen that the duty of notification is laid both upon the householder and the medical man; practically, the notifcations are received from the medical men. It happens that in the series of annual reports of successive medical officers of health for the borough, published up to the present time, the zymotic death-rates ${ }^{1}$ of the five years preceding, and the five years succeeding the adoption of the notification system are given. Quinquennial periods are, I think, sufficient to furnish fair bases of comparison and to ensure the elimination of fallacies arising out of individual years of exceptional epidemic influences, such influences, for instance, as the prevalence of particular zymotics in adjacent districts. The following is a statement of the zymotic death-rates per 1000 of the population during the last ten years.

\begin{tabular}{|c|c|c|c|c|c|}
\hline \multicolumn{6}{|c|}{ Pre-Notification Period. } \\
\hline , & $\begin{array}{c}1875 . \\
5 \cdot 1\end{array}$ & $\begin{array}{c}1876 \\
2 \cdot 9\end{array}$ & $\begin{array}{c}1877 \\
5 \cdot 1\end{array}$ & …. & $\begin{array}{r}1878 \\
6 \cdot 9\end{array}$ \\
\hline \multicolumn{6}{|c|}{ Notification Period. } \\
\hline & $\begin{array}{l}1880 . \\
3 \cdot 3\end{array}$ & $\begin{array}{c}1881 . \\
26\end{array}$ & $\begin{array}{c}1882 . \\
5.0\end{array}$ & & $\begin{array}{c}188: \\
5 \cdot 1\end{array}$ \\
\hline
\end{tabular}

A simple calculation will show that the mean zymotic rate of the first or pre-notification period is $5 \cdot 1$, as compared with 3.8 in the period during which the notification system. has been in force. The decrease $-1 \cdot 3$ per 1000 -in the mean zymotic rate of the second period, as compared with the first, is very gratifying. It will, however, be urged that there has been a considerable coincident decrease in zymotic rates all over the country. Such is indeed the case. I have tabu. lated below the zymotic rates in the fifty town districts with which Jarrow is included in the Registrar.General's returns, and with the zymotic rate of which that of Jarrow may most fairly be compared :-

\begin{tabular}{|c|c|c|c|c|c|}
\hline & & & $s$ & & \\
\hline $\begin{array}{l}1874 \\
4 \cdot 4\end{array}$ & $\cdots$ & $\begin{array}{l}1875 \\
3.5\end{array}$ & $\begin{array}{c}1876 . \\
3.3\end{array}$ & $\begin{array}{c}1877 \\
3 \cdot 1\end{array}$ & $\begin{array}{c}1878 . \\
3.8\end{array}$ \\
\hline & 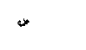 & & -1 & & \\
\hline $\begin{array}{l}379 . \\
9\end{array}$ & & $\begin{array}{c}1880 \\
377\end{array}$ & $\begin{array}{l}1881 . \\
2 \cdot 2\end{array}$ & $\begin{array}{c}1882 . \\
2 \cdot 9\end{array}$ & \\
\hline
\end{tabular}

The mean of the first quinquennial period is $3 \cdot 6$, of the second, $2 \cdot 8$; the decrease in the zymotic rate of the second period as compared with the first was 0.8 . It will be seen that the decline in the zymotic rate in Jarrow is almost double that of the fifty town districts. ${ }^{2}$ And the diminished prevalence of zymotic disease in Jarrow cannot be attributed in any degree to a proportional improvement in general sanitary conditions; the decline in the zymotic rate is not at all accompanied by a proportional decline in the general death-rate. The mean death-rate of the borough for the quinquennial period $1874-78$ was 220 per 1000 ; for the period $1879-83$ it was 20.5 , the decrease being 1.5 . Otherwise put, the proportion the decrease in the general deathrate bears to the mean death-rate of the first period is 0.068 . while the decrease in the zymotic rate is in the proportion of 0.254 to the zymotic rate of the first period.

There may be towns in which in the same period a like gratifying decrease in zymotic rates has been experienced to that which has occurred in Jarrow; hut I can hardly believe

1 Death-rates per 1000 of the population from the seven principal zymotic diseases.

It is almost certain that the population in Jarrow has increased at much more rapid rate in the last three years than is estimated by the Registrar-General's method ; if this under-estimation of the population were discounted, the decrease in the mean zymotic rate of the secon 1 quinquennial would be fully double that of the fifty town districts. 
that such decrease could have been brought about under circumstances so adverse as those in Jarrow, had it not been for the system of compulsory notification; for, in the first place, there has been in Jarrow a very rapid increase in the surface crowding of the population in the course of the last ten years. During that period the population has increased by about one-third ; and, of course, density of population is an important factor in respect of the prevalence of zymotic disease. But the most adverse circumstance has been the want of hospital accommodation for the sufficient isolation of cases of infectious disease insufficiently isolated at home. Up till the year before last, Jarrow possessed no hospital, and even now the corporation only provides hospital accommodation for the reception of cases of small-pox. The sanitary officials are thus considerably handicapped in their efforts for the prevention of the spread of infections diseases, for Jarrow is essentially a working-class town, and the lack of proper hospital accommodation is a much more grievous matter than in the case of the average town, as proper facilities for the sufficient isolation of cases of infectious disease at home are in a large proportion of cases wanting. With the compulsory notification and with hospital accommodation for, perhaps, three several infectious diseases (the provision of which the corporation has in contemplation), I have not the least doubt that a still more decided decline in the zymotic rate will be attainable in the next quinquenniad. There are defects, too, in the notification scheme adopted in Jarrow, which have detracted from the beneficial operation of the system. Thus, measles, from which disease alone there was a death-rate of 2.9 per 1000 in Jarrow last year, is not one of the diseases compulsorily notifiable under the Act. And the feeling of the medical men that they were very insufficiently remunerated for notifying. had a tendency to make them not very enthusiastic in the work. An effort has been made to amend both these matters in a local Bill at present under the consideration of Parliament.

The notification system as wrought in Jarrow implies a considerable infringement of the "privacy of the home;" but I am bound to say that the visits of the sanitary officials are invariably received at least with equanimity - usually with courtesy, and that people generally seem willing to avail themselves of the advice I proffer. Each case notified is visited on the day on which the notification is received, by the sanitary inspector, and almost every case by myself as well ; a formal notice to disinfect and a paper of simple instructions for isolation and disinfection are placed in the hands of the householder, information is given as to the times at which disinfectants may be obtained gratuitously at the Health Office, and the best practicable instructions for the isolation of the case-each in its particular circum stances-are given. I do not consider myself called upon to verify the diagnosis of the medical man in attendance; in any case, however, in which $I$ have reason to question the diagnosis, and in which a different diagnosis would involve different arrangements for isolation and disinfection, I communicate in a friendly spirit with the medical man notifying. I have in no case made the corporation a court of appeal in matters of diagnosis.

A few words in conclusion, as to the general, apart from the statistical, results of the adoption of the compulsory notification system in Jarrow. Has the working of the Act aroused the hostility of the medical men of the town to the principle of compulsory notification? A sufficient answer in the negative was afforded in an experience of a few months ago. The corporation having resolved to incorporate some amendments to the notification system at present in force in a proposed new local Act, I was desired to convene a meeting of the medical men of the town, in order to ascertain their opinion of the various sanitary clauses of the proposed Bill. For this meeting, invitations were sent out to eleven medical men practising in the town. At the meeting which took place, after five years' experience of the system, no medical man was found to oppose the principle of com. pulsory notification of infectious diseases; two medical men, however, a principal and his assistant, held that medical men should merely be required to notify diseases as "infectious," leaving to the medical officer of health the duty of diagnosing the specific nature of the disease in cases notified. In this connexion, too, I may be allowed to remark that in spite of (?) the compulsory notification system, I am on amicable terms with all the medical men in the town; though I would not admit it as an argument against the system, that the medical officer of health in any town which had adopted the scheme was not on amicable terms with individual medical men, for there are some men in the medical profession, as well as outside of it, who would quarrel with their own shadows, and in respect of whom the meekness of Moses and the patience of Job would not avail to avert a quarrel.

With regard to the alleged tendency of the compulsory notification system to lead to the concealment of the existence of cases of infectious disease, I can only say that so far as my experience has gone I have seen no evidence of anything of the sort.

South Shields.

THE AFTER-TREATMENT OF

LATERAL DISLOCATION OF THE PATELLA BY A NEW FORM OF KNEE-CAP,

WITH THE OBJECT OF PREVEN'TING RECURRENCE.

By C. YELVERTON PEARSON, M.D., M.CH., LECTURER ON DESCRIPTIVE AND SURGICAL ANATOMY, QUEEN'S COLLEGE, CORK, ETC.

THE difficulty of preventing recurrence of lateral dislocation of the patella, once it has taken place, is so universally acknowledged by surgeons that I am induced to publish an account of the success which has attended the use of a kneecap devised by me (which I shall presently describe) for the treatment of the following case.

J. S_- a lady aged twenty-six, in January, 1874, when stooping suddenly, dislocated the right patella outwards, and immediately fell ; soon afterwards she got her mother to extend the leg, when the dislocation became reduced. Next day the knee, leg, and foot became greatly swollen, and were treated with chamomile and poppy fomentations, followed by inunction of camphorated oil. She was obliged to keep the limb extended for three weeks, as the knee could not be flexed ; and seven weeks elapsed before she was able to walk. She says that some swelling has since constantly remained in the knee below the patella. About nine months afterwards dislocation occurred a second time, and subsequently on three different occasions, the exact dates of which were forgotten. The case was first seen by me in October, 1881. The history at that time was that dislocation had occurred for the sixth time about six weeks previously, while running on the lawn after a child, when she experienced a sudden start, dislocated the patella, and fell. This time great swelling also followed, and the leg could not be put to the ground, but she got better in a few weeks, when an elastic knee-cap was used; soon after this was applied great swelling took place in the leg. When seen by me there was great odema of the leg; the circumference of the knee-joint below the patella was an inch greater than its fellow; this increase was due to enlargement of the bursa beneath the ligamentum patellæ.

The following treatment was employed. I painted the knee with iodine liniment and applied a strapping over it, also a bandage from the toes. After a week the swelling of the leg was somewhat reduced, while that of the knee had almost disappeared. I then applied a Martin's elastic bandage to the leg, the use of which was continued till the oedema of the leg completely disappeared, which was not for some weeks. Knowing that the main point of treatment was to prevent a recurrence of the displacement, and not being acquainted with any suitable form of apparatus which could be worn constantly without inconvenience, I made a horseshoe knee-cap, which I shall now proceed to describe, and have illustrated by the accompanying sketch.

The appliance consists of a piece of dense poroplastic in the form of a horseshoe, the concave end of which is directed downwards, and embraces the patella pretty closely; this is covered on both sides by chamois leather, the posterior surface being markedly concave. The ends are connected below by a leather strap, with perforations for attaching it to a brass stud fixed in one end of the horseshoe. The presence of this strap permits a certain amount of separation and approximation of the ends to take place, with the movements of the joint, which could not occur if the knee-cap formed a com plete ring, while at the same time offering sufficient resistance to prevent dislocation. By altering the connexion of the stud from one hole to another the cap can be made to fit different sized joints, though on the whole it would be more advisable to have the cap made specially for each individual. Attached to the outer border are two buckles, one near the upper, the other near the lower end ; placed at corresponding 